University of South Carolina

Scholar Commons

\title{
Simulation of the Polarization Curves for Oxygen Reduction at a Rotating Disk Electrode
}

\author{
P. K. Adanuvor \\ Texas A \& M University - College Station \\ Ralph E. White \\ University of South Carolina - Columbia, white@cec.sc.edu
}

Follow this and additional works at: https://scholarcommons.sc.edu/eche_facpub

Part of the Chemical Engineering Commons

\section{Publication Info}

Journal of the Electrochemical Society, 1987, pages 1093-1098.

(c) The Electrochemical Society, Inc. 1987. All rights reserved. Except as provided under U.S. copyright law, this work may not be reproduced, resold, distributed, or modified without the express permission of The Electrochemical Society (ECS). The archival version of this work was published in the Journal of the Electrochemical Society.

http://www.electrochem.org/

DOI: $10.1149 / 1.2100622$

Publisher's Version: http://dx.doi.org/10.1149/1.2100622

This Article is brought to you by the Chemical Engineering, Department of at Scholar Commons. It has been accepted for inclusion in Faculty Publications by an authorized administrator of Scholar Commons. For more information, please contact digres@mailbox.sc.edu. 


\title{
Simulation of the Polarization Curves for Oxygen Reduction at a Rotating Disk Electrode
}

\author{
P. K. Adanuvor and R. E. White* \\ Department of Chemical Engineering, Texas A\&M University, College Station, Texas 77843
}

\begin{abstract}
The electrochemical reduction of oxygen in $1 M \mathrm{NaOH}$ solution is simulated at a rotating disk electrode. Steady-state polarization curves are presented for possible reaction schemes for the reduction process. The effect of changes in the kinetic parameters on the polarization curves is demonstrated and special attention is focused on the production of hydrogen peroxide.
\end{abstract}

The electrochemical reduction of oxygen is of special significance in electrochemical technology. It forms the basis of electrochemical combustion and so far, it has been one of the most promising methods for direct conversion of chemical energy into electrical energy. It has therefore become the focus of extensive research, particularly in relation to fuel cells (1). This reaction also plays a special role in the corrosion of metals. Other areas in which the reaction has attracted special attention are the production of hydrogen peroxide for use in the pulp and paper industry (2), the development of oxygen depolarizer cathodes for the replacement of hydrogen generating cathodes in the chlor-alkali industry (3), and the extraction of oxygen from air (4).

Cathodic reduction of oxygen is a complex electrochemical process that can proceed along two reaction paths, according to the nature of the electrode material and reaction conditions, as expressed by (i) a direct $4 e^{-}$ reaction, described by the overall equation

$$
\mathrm{O}_{2}+2 \mathrm{H}_{2} \mathrm{O}+4 e^{-}=4 \mathrm{OH}^{-} \quad U_{1}{ }^{\theta}=+0.401 \mathrm{~V}
$$

or by (ii) two consecutive $2 e^{-}$steps which can be expressed by the equations

$$
\begin{array}{cc}
\mathrm{O}_{2}+\mathrm{H}_{2} \mathrm{O}+2 e^{-}=\mathrm{HO}_{2}^{-}+\mathrm{OH}^{-} & U_{2}{ }^{\theta} \\
& =-0.0649 \mathrm{~V} \\
\mathrm{HO}_{2}^{-}+\mathrm{H}_{2} \mathrm{O}+2 e^{-}=3 \mathrm{OH}^{-} & U_{3}{ }^{\theta}=+0.867 \mathrm{~V}
\end{array}
$$

Direct $4 e^{-}$reduction of oxygen as expressed in Eq. [1] is known to occur, at least in part, on electrodes made of noble metals and pyrolyzed transition metal macrocyclics (5-7). The $2 e^{-}$reduction of oxygen by Eq. [2], proceeding with the formation of peroxide as a stable intermediate, occurs on mercury and some carbon electrodes $(8,9)$. With nondoped low ash carbons, and in the absence of any other catalysts, peroxide concentrations as high as $1 M$ are attainable (10). The peroxide intermediate can undergo further electrochemical reduction as shown by Eq. [3], especially at higher values of the applied potential. On the other hand, the peroxide intermediate may not be a stable product on some electrode materials and can spontaneously decompose to form oxygen according to the equation

$$
2 \mathrm{HO}_{2}{ }^{-}=2 \mathrm{OH}^{-}+\mathrm{O}_{2} \quad \Delta G^{\circ}{ }_{298}=-184.09 \mathrm{~kJ} / \mathrm{mol}
$$

This reaction has been known to occur on silver and platinum electrodes $(11,12)$. When both the direct $4 e^{-}$process and the consecutive $2 e^{-}$process occur on the same electrode, the reduction process is said to involve the parallel mechanism. Oxygen reduction occurs by the parallel mechanism on platinum with the direct $4 e^{-}$reduction predominant in the absence of impurities (5). Depending on the nature of the electrode material and the operating environment and conditions, various parallel-consecutive combinations are possible.

Peroxide intermediate formation in the reduction of oxygen is of vital importance in the evaluation of the performance of electrocatalysts for the oxygen cathode. In some applications such as $\mathrm{O}_{2} /$ air-cathodes in fuel cells,

*Electrochemical Society Active Member. the peroxide reaction is undesirable because it leads to a reduction in the operating cell efficiency. Peroxide also has a tendency to accelerate the oxidation of the catalyst and its support leading to early electrode failure. In other cases, the peroxide may be the desired end product in the electrochemical reduction of oxygen $(2,9)$. Of primary importance is the decomposition of peroxide by reaction [4]. This reaction is catalyzed by many substrates, the most effective being silver and platinum black. This reaction is electrochemically unproductive but can be very useful in suppressing the peroxide concentration formed at the electrode. Knowledge of the fraction of the total current involved in peroxide generation and the role of catalytic decomposition of peroxide are of special importance in electrokinetic studies of the oxygen electrode. Otherwise, it will not be possible to construct meaningful current-potential plots and to interpret them properly.

McIntyre $(13,14)$ developed a simple model at the rotating disk electrode (RDE) to elucidate the kinetics of an oxygen electrode reaction in which peroxide is formed as an intermediate reduction product that undergoes a surface catalyzed decomposition. Blurton and McMullin (15) applied McIntyre's model to elucidate the role of hydrogen peroxide in the reduction of oxygen on platinum and to analyze and measure the effect of peroxide decomposition on the limiting current. Appleby and Savy (16) derived kinetic equations for oxygen reduction reactions involving catalytic decomposition of hydrogen peroxide with direct application to porous and rotating ring disk electrodes. Diagnostic criteria based on the rotating ring disk electrode (RRDE) technique have been developed to distinguish between the consecutive and parallel pathways for oxgyen reduction and to elucidate the mechanisms of the reduction process (17-19). Recently, Jakobs et al. (20) extended the theory of the $R R D E$ to oxygen reduction at polypyrrole electrodes in the case where substantial amounts of hydrogen peroxide are present in the bulk of the electrolyte. With the exception of McIntyre's simple model $(13,14)$ which provides analytical expressions to generate current/ potential curves for a single electrode reaction and for consecutive electrochemical reactions coupled to a surface catalyzed chemical regenerative reaction, other models have dealt more or less with analysis of the role of intermediates, with provision of diagnostic criteria to distinguish between the various reaction pathways, and with the elucidation of the reaction mechanism for oxygen reduction. What these models are lacking is the capability to simulate the complex system of reactions of oxygen and the ability to predict the behavior of this system under various conditions of practical interest. In engineering applications, it is often necessary to predict the behavior of complex electrochemical systems by developing suitable mathematical models to simulate important features of the system over a wide range of a given variable. In this way, much more meaningful evaluation of the system can be made and a better understanding of the processes taking place can be gained.

In this paper, we simulate the complex system of reactions for oxygen reduction in alkaline electrolytes using 
the general model developed previously for electrochemical reactions at the RDE (21) to obtain steady-state current/potential curves that represent the various mechanistic pathways for the oxygen cathode. The effect of changes in the kinetic parameters on the simulated polarization curves is demonstrated and special attention is focused on the production of peroxide and on the role of unwanted side reactions on the production process.

\section{Model Equations}

Under steady-state conditions the material balance equation for species $i$ within the diffusion layer of a RDE is given by (21)

$$
\frac{D_{\mathrm{i}}}{D_{\mathrm{R}}} c_{\mathrm{i}}^{\prime \prime}+3 \xi^{2} c_{\mathrm{i}}^{\prime}+\frac{z_{\mathrm{i}} u_{\mathrm{i}} \mathbf{F}}{D_{\mathrm{R}}}\left[\mathrm{c}_{\mathrm{i}} \Phi^{\prime \prime}+c_{\mathrm{i}} \Phi^{\prime}\right]+\frac{\delta_{\mathrm{D}}{ }^{2}}{D_{\mathrm{R}}} R_{\mathrm{l}}=0
$$

where the primes denote differentiation with respect to $\xi$ and the $R_{\mathrm{i}}$ term denotes the rate expression for the production of species $i$ by a homogeneous reaction. For the oxygen electrode, $R_{\mathrm{i}}$ is assumed to be zero since the rate of decomposition of peroxide in solution is relatively slow (22). The electroneutrality condition

$$
\sum_{\mathbf{i}} z_{\mathrm{i}} c_{\mathrm{i}}=0
$$

completes the set of equations needed to solve for the $c_{\mathbf{i}}$ and $\Phi$ unknowns. The boundary conditions in the bulk solution and at the electrode surface are, respectively, at

$$
\xi=2 \quad c_{\mathrm{i}}=c_{\mathrm{i}, \infty} \quad \text { and } \Phi=\Phi_{\mathrm{re}}
$$

and

$$
-\left.N_{\mathrm{t}}\right|_{\xi=0}=\sum_{\mathrm{j}=1}^{\mathrm{m}} \frac{s_{\mathrm{i}, \mathrm{j}} i_{\mathrm{j}}}{n_{\mathrm{j}} \mathbf{F}}+s_{\mathrm{i}, 4} r_{\mathrm{s}}
$$

where $r_{\mathrm{s}}$ is the catalytic rate of decomposition of peroxide at the electrode surface and $m$ is the number of charge-transfer reactions occurring at the electrode surface, $s_{i, j}$ is the stoichiometric coefficient of species $i$, and $n_{\mathrm{j}}$ the number of electrons transferred in reaction $j$, when written in the form

$$
\sum_{\mathrm{i}} s_{\mathrm{ij}} M_{\mathrm{i}}^{\mathrm{z}_{\mathrm{i}}} \rightarrow n_{\mathrm{j}} \mathrm{e}^{-}
$$

Kinetic equations.-The kinetic rate equations for the electrochemical reactions at the electrode surface are approximated by the Butler-Volmer expression for the current density

$$
i_{\mathrm{j}}=i_{0 \mathrm{j}}\left[\exp \left(\frac{\alpha_{\mathrm{aj}} \mathbf{F}}{R T} \eta_{\mathrm{j}}\right)-\exp \left(-\frac{\alpha_{\mathrm{cj}} \mathbf{F}}{R T} \eta_{\mathrm{j}}\right)\right]
$$

where

$$
\eta_{\mathrm{j}}=\Phi_{\mathrm{met}}-\Phi_{\mathrm{re}}-\left(\Phi_{\mathrm{o}}-\Phi_{\mathrm{re}}\right)-U_{\mathrm{j}, \mathrm{ref}}
$$

The concentration dependence of the exchange current density is expressed as

$$
i_{0 \mathrm{j}}=i_{\mathrm{oj}, \mathrm{ref}} \prod_{\mathrm{i}}\left(\frac{c_{\mathrm{i}, 0}}{c_{\mathrm{i}, \mathrm{ref}}}\right)^{\gamma \mathrm{il}}
$$

where the exponents take the values

$$
\gamma_{\mathrm{ij}}=q_{\mathrm{ij}}+\frac{\alpha_{\mathrm{cj}} s_{\mathrm{ij}}}{n_{\mathrm{j}}}
$$

with $q_{i j}=-s_{i j}$ for a cathodic reactant and zero for an anodic reactant. Also, the apparent transfer coefficients for reaction $j$ sum up to the number of electrons transferred in that reaction, that is

$$
\alpha_{\mathbf{a j}}+\alpha_{\mathrm{cj}}=n_{\mathrm{j}}
$$

The open-circuit potential of reaction $j$ at the reference concentrations relative to a standard reference electrode of a given kind is expressed as

$$
\begin{aligned}
U_{\mathrm{j}, \text { ref }}=U_{\mathrm{j}}^{\theta}-U_{\mathrm{re}}^{\theta}-\frac{R T}{n \mathbf{F}} \sum_{\mathrm{i}} s_{\mathrm{ij}} \ln \left(\frac{c_{\mathrm{i}, \text { ref }}}{\rho_{\mathrm{o}}}\right) \\
+\frac{R T}{n_{\mathrm{re}} \mathbf{F}} \sum_{\mathrm{i}} s_{\mathrm{ij}} \ln \left(\frac{c_{\mathrm{i}, \mathrm{re}}}{\rho_{\mathrm{o}}}\right)
\end{aligned}
$$

The total current density is the sum of the partial current densities

$$
i=\sum_{\mathbf{j}} i_{\mathbf{j}}
$$

The catalytic rate of decomposition of peroxide at the electrode surface is expressed as

$$
r_{\mathrm{s}}=-k_{\mathrm{h}} \mathrm{c}^{p} \mathrm{HO}_{2^{-}, 0}
$$

where the reaction order, $p$, can be a fraction or a whole number $(11,23)$ and where the rate constant $k_{\mathrm{h}}$ is assumed to be independent of the applied potential.

The set of governing equations subject to the given boundary conditions can be solved numerically as described previously (21) to yield the values for $c_{\mathrm{i}}$ and $\Phi$ and

\begin{tabular}{|c|c|c|c|c|}
\hline Parameters & Reaction [1] & Reaction [2] & Reaction [3] & Reaction [4] \\
\hline $\begin{array}{l}\boldsymbol{\alpha}_{\mathrm{cj}} \\
i_{\mathrm{oj} \cdot \text { ref }}\left(\mathrm{A} / \mathrm{cm}^{2}\right) \\
U_{\mathrm{j}}^{\theta^{a}}(\mathrm{~V}) \\
n_{\mathrm{j}} \\
k_{\mathrm{h}}(\mathrm{cm} / \mathrm{s})\end{array}$ & $\begin{array}{l}0.5-1.5 \\
10^{-8}-10^{-14} \\
0.401 \\
4\end{array}$ & $\begin{array}{l}0.8-1.6 \\
10^{-6}-10^{-12} \\
-0.0649 \\
2\end{array}$ & $\begin{array}{l}0.10-0.20 \\
10^{-8}-10^{-14} \\
0.870 \\
2\end{array}$ & $10^{-6}-10^{4}$ \\
\hline $\begin{array}{l}\text { Solution properties } \\
c_{\mathrm{i}, \text { ret }}\left(\mathrm{mol}^{2} / \mathrm{cm}^{3}\right) \\
D_{\mathrm{i}}\left(\mathrm{cm}^{2} / \mathrm{s}\right)\end{array}$ & $\begin{array}{l}\mathrm{O}_{2} \\
8.34 \times 10^{-7} \\
1.79 \times 10^{-5}\end{array}$ & $\begin{array}{l}\mathrm{HO}_{2}^{-} \\
1.377 \times 10^{-14} \\
5.00 \times 10^{-6 \mathrm{~b}}\end{array}$ & $\begin{array}{l}\mathrm{Na}^{+} \\
0.001 \\
1.975 \times 10^{-5 \mathrm{c}}\end{array}$ & $\begin{array}{l}\mathrm{OH}^{-} \\
0.001 \\
1.200 \times 10^{-5 \mathrm{c}}\end{array}$ \\
\hline $\begin{array}{l}\mathbf{F}=96,487.0 \mathrm{C} / \mathrm{mol} \\
R=8.314 \mathrm{~J} / \mathrm{K}-\mathrm{mol}\end{array}$ & $T=298.15 \mathrm{~K}$ & $\rho_{0}=0.001 \mathrm{~kg} / \mathrm{cm}^{3}$ & $\Omega=3600 \mathrm{rpm}$ & $\nu=0.012 \mathrm{~cm}^{2} / \mathrm{s}$ \\
\hline
\end{tabular}
thus, for $c_{i, o}$ and $\Phi_{0}$ from which the reaction rates at specified values of the applied potential, $E_{\text {appl }}$ (where $E_{\text {appl }}=$ $\Phi_{\text {met }}-\Phi_{\text {re }}$ ) can be determined. The net current density is the sum of the partial current densities as expressed by Eq. [16].

\section{Results and Discussion}

Table I is a list of parameter values used to simulate the electrochemical reduction of oxygen in $1.0 \mathrm{M} \mathrm{NaOH}$ solution at $25^{\circ} \mathrm{C}$. Diffusion coefficient and solubility data for $\mathrm{O}_{2}$ in $\mathrm{KOH}(24,25)$ were used since literature values for $\mathrm{NaOH}$ were not readily available. The simulation was carried out for $(i)$ the overall reaction scheme for the re-

Table I. Parameter values for simulating the polarization curves for $\mathrm{O}_{2}$ reduction

a Values taken from (28).

V Values taken from (29).

c Values taken from Table 75-1 (30). 


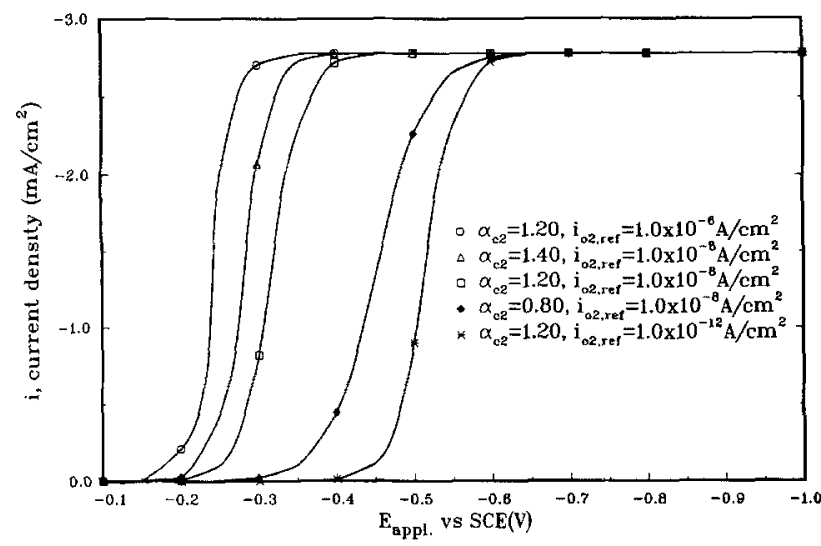

Fig. 1. $\mathrm{O}_{2}$ reduction to stable $\mathrm{HO}_{2}^{-}$species at $\Omega=3600 \mathrm{rpm}$

duction of $\mathrm{O}_{2}$ as given by Eq. [1], [2], [3], and [4], (ii) the parallel mechanism without peroxide decomposition, given by Eq. [1], [2], and [3], (iii) the consecutive mechanism with and without peroxide decomposition given by Eq. [2], [3], and [4] and Eq. [2] and [3], respectively, (iv) the direct $4 e^{-}$mechanism given by Eq. [1] and the peroxide step, Eq. [2]. The results are presented below.

$\mathrm{O}_{2}$ reduction to peroxide: $\mathrm{O}_{2}+\mathrm{H}_{2} \mathrm{O}+2 e^{-}=\mathrm{HO}_{2}^{-}+$ $\mathrm{OH}^{-}$.-Figure 1 illustrates the case where peroxide is formed as an end product without undergoing further decomposition. A change in the kinetic parameters $\left(i_{o 2, \text { ref }}\right.$ and $\alpha_{\mathrm{c} 2}$ ) for this reaction leads to a shift in the half-wave potential. A decrease in $i_{02 \text {,ref, }}$ or $\alpha_{\mathrm{c} 2}$ shifts the half-wave potential further in the negative direction. The more cathodic the half-wave potential, the slower the rate at which limiting current conditions is attained. It must be borne in mind that the apparent transfer coefficient $\alpha_{a j}$ or $\alpha_{c j}$ affects the slope of the rising portion of the polarization curve (the Tafel region), while the exchange current density affects the slope of the linear region in the vicinity of the open-circuit potential. The direct $4 e^{-}$process for $\mathrm{O}_{2}$ reduction is exactly analogous to the $2 e^{-}$reduction of $\mathrm{O}_{2}$ to $\mathrm{HO}_{2}{ }^{-}$presented here; the only exception is that the limiting current density of the former is twice the magnitude of the latter.

$\mathrm{O}_{2}$ reduction to $\mathrm{HO}_{2}^{-}$with catalytic decomposition of $\mathrm{HO}_{2}^{-}$- -

$$
\begin{gathered}
\mathrm{O}_{2}+\mathrm{H}_{2} \mathrm{O}+2 e^{-}=\mathrm{HO}_{2}^{-}+\mathrm{OH}^{-} \\
\mathrm{pHO}_{2}^{-}=\frac{p}{2} \mathrm{O}_{2}+p \mathrm{OH}^{-}
\end{gathered}
$$

Figure 2 shows the effect of catalytic decomposition of peroxide on the reduction of $\mathrm{O}_{2}$ to $\mathrm{HO}_{2}{ }^{-}$. This situation

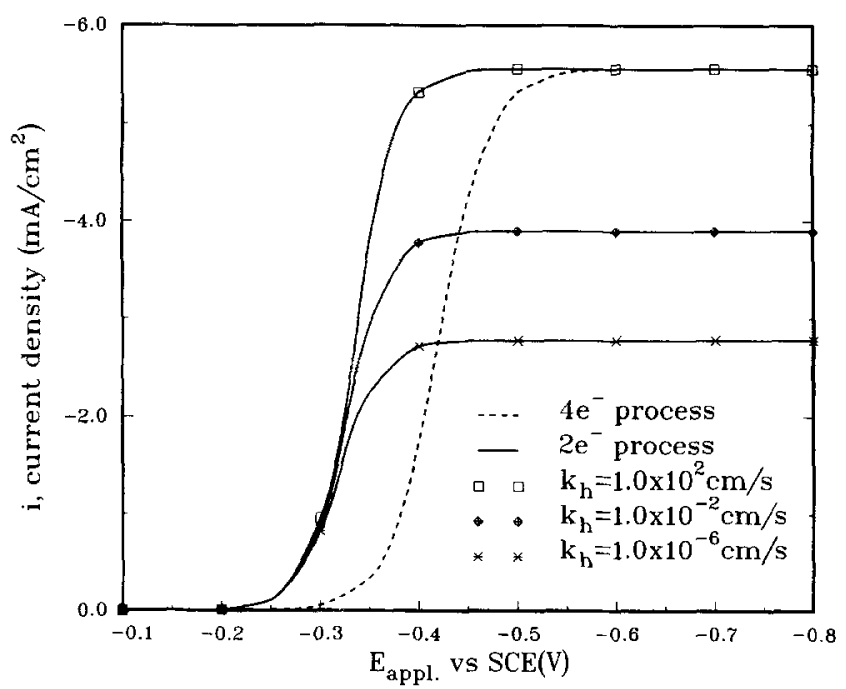

Fig. 2. $\mathrm{O}_{2}$ reduction to $\mathrm{HO}_{2}{ }^{-}$with catalytic regenerative reaction. Comparison to the direct $4 \mathrm{e}^{-}$process. Simulation parameters: $i_{02 \text {.ref }}=$ $1.0 \times 10^{-8} \mathrm{~A} / \mathrm{cm}^{2}, \alpha_{\mathrm{c} 2}=1.20$ for $2 \mathrm{e}^{-}$process, and $i_{02, \mathrm{ref}}=1.0 \times 10^{-12}$ $\mathrm{A} / \mathrm{cm}^{2}, \alpha_{\mathrm{c} 1}=1.00$ for $4 \mathrm{e}^{-}$process, $\Omega=3600 \mathrm{rpm}$.

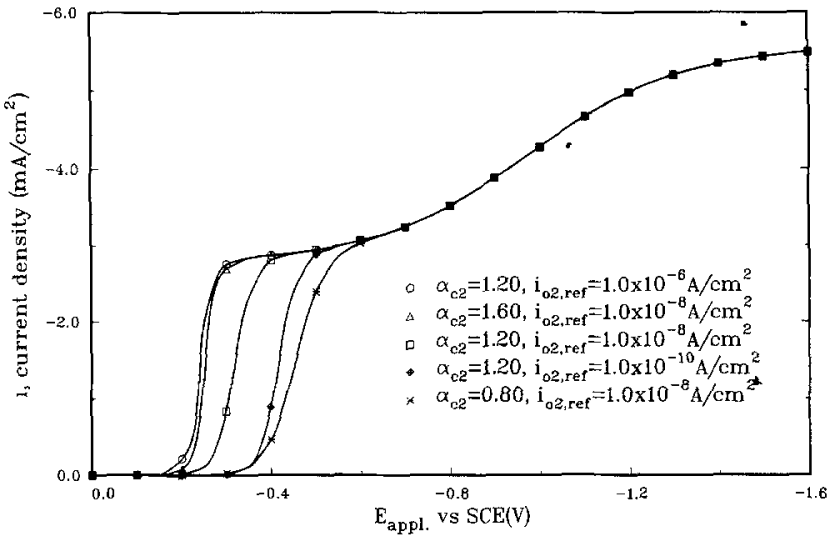

Fig. 3. $\mathrm{O}_{2}$ reduction to $\mathrm{OH}^{-}$via the two-step $2 \mathrm{e}^{-}$series mechanism. Effect of $i_{02, \text { ref }}$ and $\alpha_{\mathrm{az}}$ on the polarization curves. Simulation parameters: $i_{03, \text { ref }}=1.0 \times 10^{-12} \mathrm{~A} / \mathrm{cm}^{2}, \alpha_{\mathrm{c} 3}=0.15, \Omega=3600 \mathrm{rpm}$.

normally occurs on carbon electrodes with a peroxide decomposition catalyst. First-order decomposition kinetics were assumed, although other orders (half and second) give similar results. At low peroxide decomposition rates, the decomposition process is too slow to cause any noticeable effect on the polarization curves, in which case, much of the peroxide could be lost to the solution by diffusion. As the decomposition rate increases, there is an increase in the limiting current density. At a very high peroxide decomposition rate $k_{\mathrm{h}} \geq 10^{2}$, the limiting current becomes equal to that of the direct $4 e^{-}$process shown by the dashed curve. Under this condition, the peroxide decomposes very rapidly, possibly before it desorbs from the surface to diffuse into the solution. These results indicate that in cases where the $4 e^{-}$reduction of oxygen is the desired reaction, a good peroxide decomposition catalyst on a suitable substrate such as carbon, where the $2 e^{-}$process occurs, can accomplish the same results.

$\mathrm{O}_{2}$ reduction to $\mathrm{HO}_{2}{ }^{-}$with electrochemical reduction of $\mathrm{HO}_{2}^{-}$-(series or consecutive process)

$$
\begin{gathered}
\mathrm{O}_{2}+\mathrm{H}_{2} \mathrm{O}+2 e^{-}=\mathrm{HO}_{2}^{-}+\mathrm{OH}^{-} \\
\mathrm{HO}_{2}^{-}+\mathrm{H}_{2} \mathrm{O}+2 e^{-}=3 \mathrm{OH}^{-}
\end{gathered}
$$

The two-step reduction of oxygen to $\mathrm{OH}^{-}$via peroxide intermediate commonly occurs on carbon electrodes at high overpotential values. Figures 3 and 4 present the polarization curves for this two-step model. The values of the kinetic parameters dictate the extent of coupling of the two reactions and thereby determine whether one or two limiting current regions are observed. In Fig. 3 , the effect of changes in the kinetic paramters for reaction [2] on the polarization curves appears to be limited to the less negative potential regions. On the other hand, changes in the kinetic parameters for reaction [3] extend



Fig. 4. $\mathrm{O}_{2}$ reduction to $\mathrm{OH}^{-}$via the two-step $2 \mathrm{e}^{-}$series mechanism. Effect of $i_{03, \text { ret }}$ and $\alpha_{c 3}$ on the polarization curves. Simulation parameters: $i_{02, \text { ref }}=1.0 \times 10^{-8} \mathrm{~A} / \mathrm{cm}^{2}, \alpha_{\mathrm{c} 2}=1.20, \Omega=3600 \mathrm{rpm}$. 
over the whole range of the potential region, Fig. 4 . This results in polarization curves characterized by a single wave with one limiting current region at lower values of $\alpha_{\mathrm{c3}}$ or $i_{03, \mathrm{ref}}$, two limiting current regions at intermediate values of these parameters and another limiting current region at high values of the parameters, corresponding respectively to the reduction of $\mathrm{O}_{2}$ to peroxide by reaction [2], the reduction of $\mathrm{O}_{2}$ to $\mathrm{OH}^{-}$via peroxide intermediate, reactions [2] and [3], and the direct reduction of $\mathrm{O}_{2}$ to $\mathrm{OH}^{-}$by reaction [1].

$\mathrm{O}_{2}$ reduction to $\mathrm{HO}_{2}{ }^{-}$with both catalytic and electrolytic decomposition of $\mathrm{HO}_{2}{ }^{-}$.- - (consecutive mechanism with a catalytic regenerative reaction)

$$
\begin{gathered}
\mathrm{O}_{2}+\mathrm{H}_{2} \mathrm{O}+2 e^{-}=\mathrm{HO}_{2}^{-}+\mathrm{OH}^{-} \\
\mathrm{HO}_{2}^{--}+\mathrm{H}_{2} \mathrm{O}+2 e^{-}=3 \mathrm{OH}^{-} \\
\mathrm{pHO}_{2}^{-}=\frac{p}{2} \mathrm{O}_{2}+p \mathrm{OH}^{-}
\end{gathered}
$$

This case is similar to the case in Fig. 2 where no electrolytic decomposition of peroxide occurs. As shown in Fig. 5, the increase in the catalytic rate of decomposition of peroxide results in an enhancement of the limiting current in the region where peroxide is generally produced $(-0.35$ to $-0.8 \mathrm{~V})$. At very high rates of peroxide decomposition, the limiting current density of the two-step model essentially coincides with that of the one-step direct $4 e^{-}$model.

Parallel mechanism without catalytic decomposition of peroxide.-

$$
\begin{gathered}
\mathrm{O}_{2}+2 \mathrm{H}_{2} \mathrm{O}+4 e^{-}=4 \mathrm{OH}^{-} \\
\mathrm{O}_{2}+\mathrm{H}_{2} \mathrm{O}+2 e^{-}=\mathrm{HO}_{2}^{-}+\mathrm{OH}^{-} \\
\mathrm{HO}_{2}^{-}+2 \mathrm{H}_{2} \mathrm{O}+2 e^{-}=3 \mathrm{OH}^{-}
\end{gathered}
$$

This mechanism demonstrates the case where the direct $4 e^{-}$process and the two-step $2 e^{-}$process are competing for the $\mathrm{O}_{2}$ species at the surface of the electrode. At certain values of the kinetic parameters, reaction [1] dominates the competition for $\mathrm{O}_{2}$ at the electrode. Consequently, the fraction of $\mathrm{O}_{2}$ going through the peroxide step by reactions [2] and [3], will be small compared to the former case. The direct $4 e^{-}$process will prevail and as shown in Fig. 6-8, a single plateau corresponding to the limiting current density of the $4 e^{-}$process is observed. On the other hand, if reaction [2] dominates the competiton for $\mathrm{O}_{2}$, the two-step $2 e^{-}$process is likely to prevail, resulting in a polarization curve with a limiting current density corresponding to the $2 e^{-}$process at lower values of the applied potential and possibly another limiting current density plateau corresponding to the $4 e^{-}$process at higher values of the applied potential. Between these two extreme cases, polarization curves corresponding to the simultaneous participation of the direct $4 e^{-}$process and the two-step $2 e^{-}$process are ob-

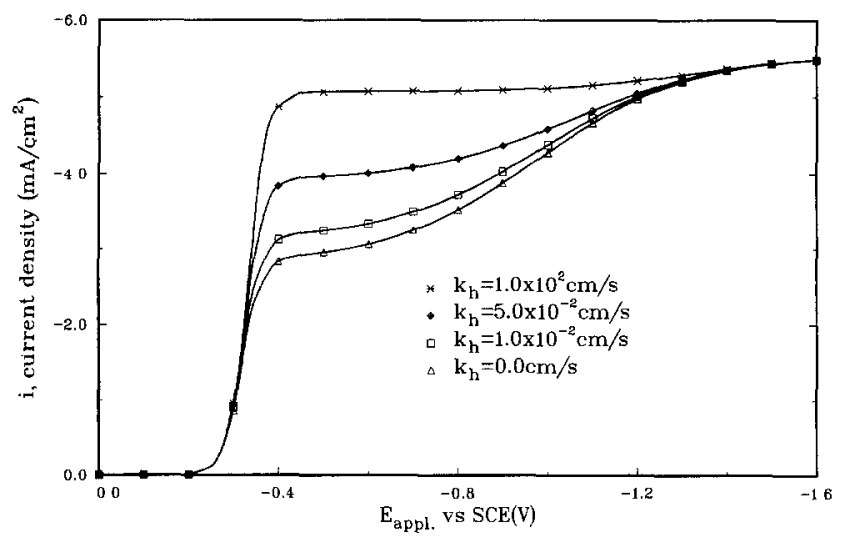

Fig. 5. $\mathrm{O}_{2}$ reduction to $\mathrm{OH}^{-}$via the two-step $2 e^{-}$series mechanism with catalytic regenerative reaction. Simulation parameters: $i_{02 \text {, ref }}=$ $1.0 \times 10^{-8} \mathrm{~A} / \mathrm{cm}^{2}, \alpha_{\mathrm{c} 2}=1.20, i_{03, \mathrm{ref}}=1.0 \times 10^{-12} \mathrm{~A} / \mathrm{cm}^{2}, \alpha_{\mathrm{c} 3}=0.15$, $\Omega=3600 \mathrm{rpm}$.

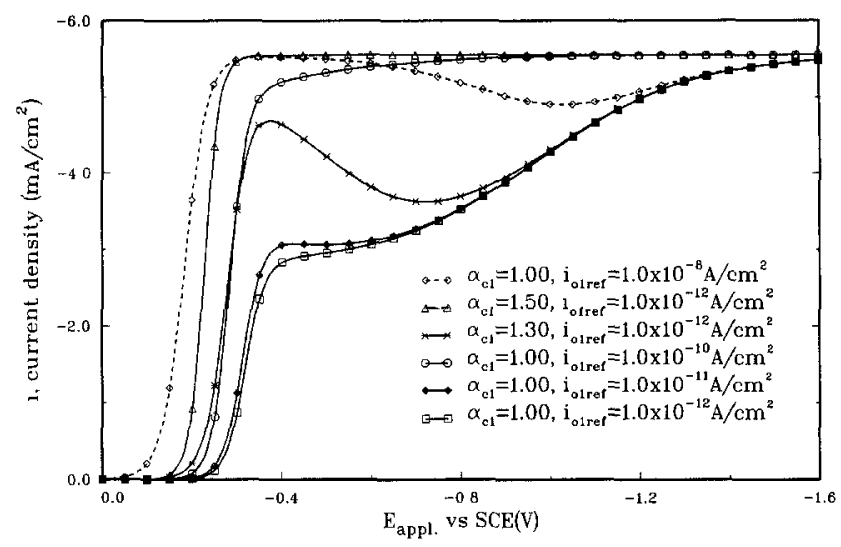

Fig. 6. $\mathrm{O}_{2}$ reduction to $\mathrm{OH}^{-}$via the parallel mechanism without $\mathrm{HO}_{2}^{-}$ regenerative reaction. Effect of $i_{01, \text { ref }}$ and $\alpha_{c 1}$ on the polarization curves. Simulation parameters: $i_{02, \text { ref }}=1.0 \times 10^{-8} \mathrm{~A} / \mathrm{cm}^{2}, \alpha_{\mathrm{c} 2}=1.20$, $i_{\mathrm{os}, \mathrm{ref}}=1.0 \times 10^{-12} \mathrm{~A} / \mathrm{cm}^{2}, \alpha_{\mathrm{c} 3}=0.15, \Omega=3600 \mathrm{rpm}$.

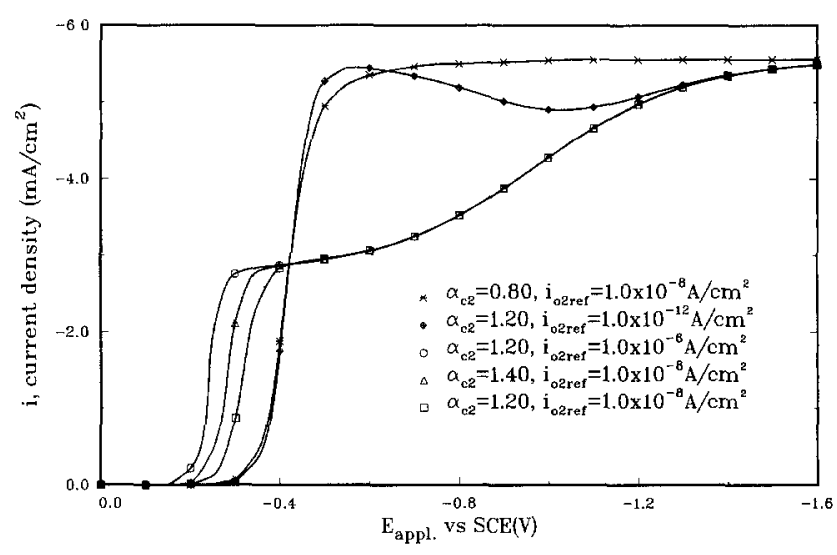

Fig. 7. $\mathrm{O}_{2}$ reduction to $\mathrm{OH}^{-}$via the parallel mechanism without $\mathrm{HO}_{2}^{-}$ regenerative reaction. Effect of $i_{02, \text { ref }}$ and $\alpha_{c 2}$ on the polarization curves. Simulation parameters: $i_{01 . \mathrm{ref}}=1.0 \times 10^{-12} \mathrm{~A} / \mathrm{cm}^{2}, \alpha_{\mathrm{c} 1}=1.00$, $i_{03, \text { ref }}=1.0 \times 10^{-12} \mathrm{~A} / \mathrm{cm}^{2}, \alpha_{\mathrm{e} 3}=0.15, \Omega=3600 \mathrm{rpm}$.

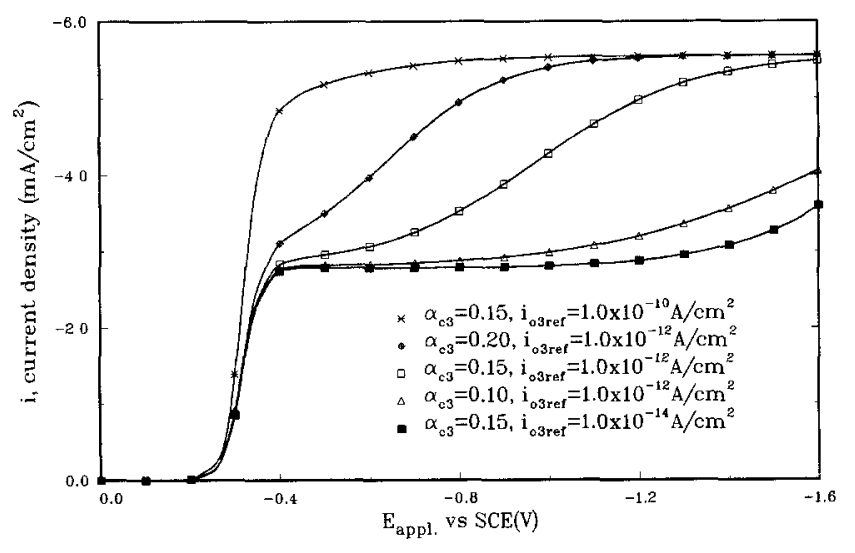

Fig. 8. $\mathrm{O}_{2}$ reduction to $\mathrm{OH}^{-}$via the parallel mechanism without $\mathrm{HO}_{2}{ }^{-}$ regenerative reaction. Effect of $i_{03, \text { ref }}$ and $\alpha_{c 3}$ on the polarization curves. Simulation parameters: $i_{01, \mathrm{ref}}=1.0 \times 10^{-12} \mathrm{~A} / \mathrm{cm}^{2}, \alpha_{\mathrm{c} 1}=1.00$, $i_{02, \text { ref }}=1.0 \times 10^{-8} \mathrm{~A} / \mathrm{cm}^{2}, \alpha_{\mathrm{c} 1}=1.20, \Omega=3600 \mathrm{rpm}$.

served. At certain values of the kinetic parameters, a hump is observed in the polarization curves at intermediate regions of the applied potential as demonstrated in Fig. 6 and 7. A close scrutiny of the kinetic parameters indicates that the humps occur when $i_{01, \text { ref }}$ and $i_{02 \text {,ref }}$ are about the same order of magnitude. In other words, humps occur when reactions [1] and [2] compete for the $\mathrm{O}_{2}$ species at the electrode at nearly the same rate. To understand further the phenomenon of hump formation, we examine the partial current density plot for a typical case in Fig. 6 where a hump is observed. The plots are displayed in Fig. 9. At lower values of the applied potential, $\mathrm{O}_{2}$ is reduced mainly through reaction [1]. However, 


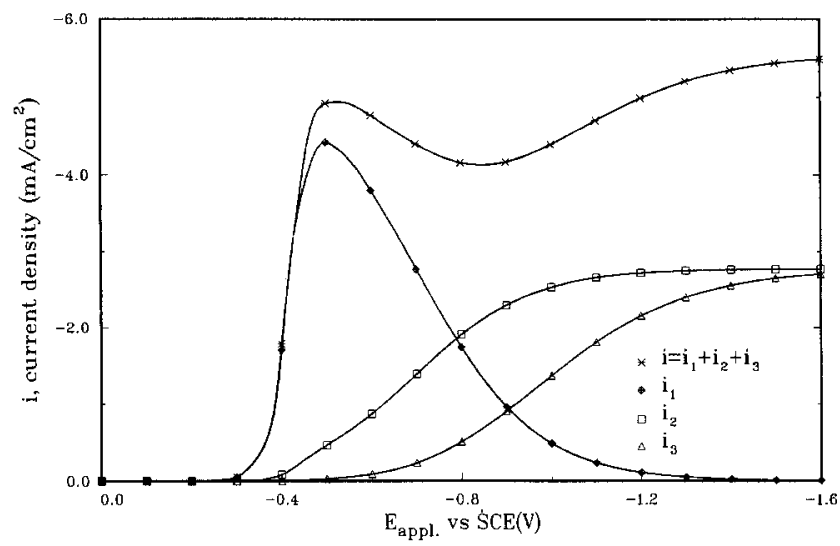

Fig. 9. Partial current density plot for the parallel mechanism for the case where a hump is formed. Simulation parameters: $i_{01, \text { ref }}=2.0 \times$ $10^{-10} \mathrm{~A} / \mathrm{cm}^{2}, \alpha_{\mathrm{c} 1}=1.00, i_{02, \text { ref }}=1.0 \times 10^{-8} \mathrm{~A} / \mathrm{cm}^{2}, \alpha_{\mathrm{c} 2}=1.20, i_{03, \text { ref }}$ $=1.0 \times 10^{-12} \mathrm{~A} / \mathrm{cm}^{2}, \alpha_{\mathrm{c} 3}=0.15, \Omega=3600 \mathrm{rpm}$.

as the potential increases, the fraction of $\mathrm{O}_{2}$ reduced by reaction [1] attains a maximum and then decreases very rapidly while the proportion reduced by reaction [2] increases steadily. The combined effect of the two processes leads to a depression in the polarization curve in the intermediate potential region resulting in the hump. Such polarization curves have been observed experimentally (26).

Parallel mechanism with peroxide decomposition (comprehensive model).-

$$
\begin{gathered}
\mathrm{O}_{2}+2 \mathrm{H}_{2} \mathrm{O}+4 e^{-}=4 \mathrm{OH}^{-} \\
\mathrm{O}_{2}+\mathrm{H}_{2} \mathrm{O}+2 e^{-}=\mathrm{HO}_{2}^{-}+\mathrm{OH}^{-} \\
\mathrm{HO}_{2}^{-}+\mathrm{H}_{2} \mathrm{O}+2 e^{-}=3 \mathrm{OH}^{-} \\
\mathrm{pHO}_{2}^{-}=\frac{p}{2} \mathrm{O}_{2}+p \mathrm{OH}^{-}
\end{gathered}
$$

In order to determine the effect of peroxide decomposition on the overall kinetics, the kinetic parameters were chosen so that the peroxide route would prevail over the direct $4 e^{-}$route. Figure 10 shows the effect of peroxide decomposition on the overall kinetics with the peroxide regenerative reaction assuming a half-, first-, and second-order kinetics, respectively. An enhancement of the limiting current is observed in the low and intermediate potential regions ( $c f$. Fig. 5). The rate constants for the regenerative reaction were chosen to show clearly the effect of the individual rate expressions on the overall kinetics. It must be emphasized that, in general, each rate expression exhibits the same pattern of behavior on the polarization curves. That is, at very low values of $k_{n}$, practically no noticeable effect on the polarization curves is observed, but an enhancement of the

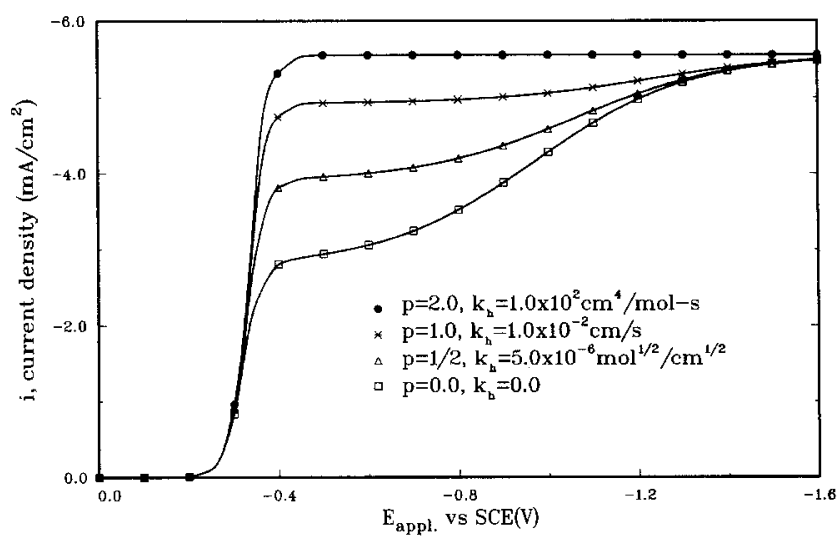

Fig. 10. $\mathrm{O}_{2}$ reduction to $\mathrm{OH}^{-}$via the parallel mechanism with $\mathrm{HO}_{2}^{-}$ regenerative reaction. Simulation parameters: $i_{01, \text { ref }}=1.0 \times 10^{-12}$ $\mathrm{A} / \mathrm{cm}^{2}, \alpha_{c 1}=1.00, i_{02, \text { ref }}=1.0 \times 10^{-8} \mathbf{A} / \mathrm{cm}^{2}, \alpha_{c 2}=1.20, i_{03, \text { ref }}=1.0$ $\times 10^{-12} \mathrm{~A} / \mathrm{cm}^{2}, \alpha_{\mathrm{e} 3}=0.15, \Omega=3600 \mathrm{rpm}$.

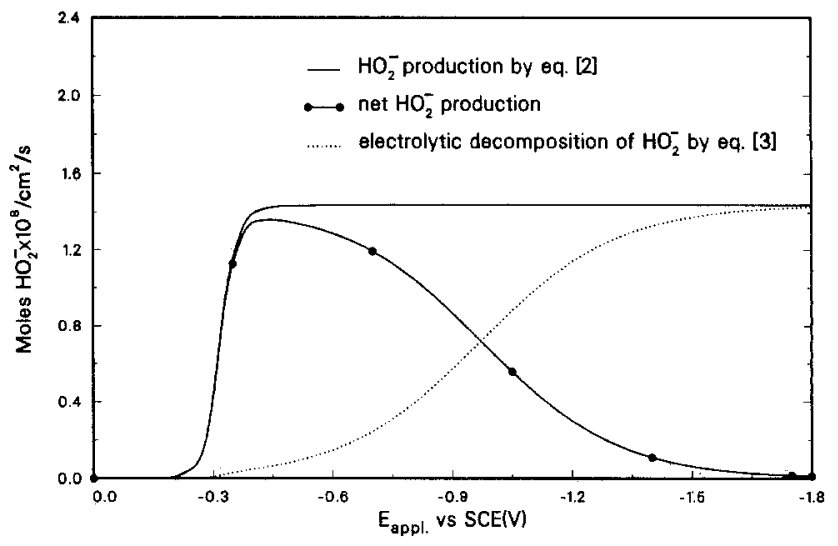

Fig. 11. Production of peroxide in the absence of catalytic decomposition of peroxide. Simulation parameters: $i_{02, \text { ref }}=1.0 \times 10^{-8} \mathrm{~A} / \mathrm{cm}^{2}$ $\alpha_{c 2}=1.20, i_{03, \mathrm{ref}}=1.0 \times 10^{-12} \mathrm{~A} / \mathrm{cm}^{2}, \alpha_{c 3}=0.15, \Omega=3600 \mathrm{rpm}$.

limiting current from the $2 e^{-}$process to the $4 e^{-}$process becomes apparent as $k_{\mathrm{n}}$, becomes very large.

Peroxide production: $\mathrm{O}_{2}+\mathrm{H}_{2} \mathrm{O}+2 e^{-}=\mathrm{HO}_{2}^{-}+\mathrm{OH}^{-}$ Hydrogen peroxide is an important industrial chemical that can be produced by the electrolytic reducton of oxygen. Berl (27) was the first to realize the preparation of hydrogen peroxide at technically feasible current densities on active carbon electrodes. However, attempts to produce hydrogen peroxide economically by this process have not been successful. Nevertheless, attention remains focused on the practical utility of this technique $(2,8)$. The desired reaction for the preparation of peroxide by the reduction of $\mathrm{O}_{2}$ is reaction [2] and the occurrence of this reaction has been established on some carbon electrodes (27). However, because of the complexity of the oxygen reaction, unwanted side reactions do occur. In this section we simulate the production of hydrogen peroxide by this technique and examine the effect of the side reactions on the production process.

In Fig. 11, the plain solid curve represents the production rate of peroxide in the absence of unwanted perox ide decomposition reactions. But as shown by the dotted curve, the peroxide can undergo further electrolytic reduction by reaction [3] particularly at higher overpotentals. The net effect is a reduction in the overall production rate of peroxide as indicated by the solid curve with the solid circles. The maximum production rate oc curs in the vicinity of $-0.4 \mathrm{~V} v s$. SCE, and in practice, this is the region in which the applied potential should be set.

Another unwanted reaction which provides a much greater problem in the preparation of hydrogen peroxide by this technique is reaction [4]. The explanation for this can be attributed to the fact that this reaction is consider ably catalyzed by a variety of both homogeneous and heterogeneous catalysts including some impurities present in the reaction system. The dash curve in Fig. 12 rep-

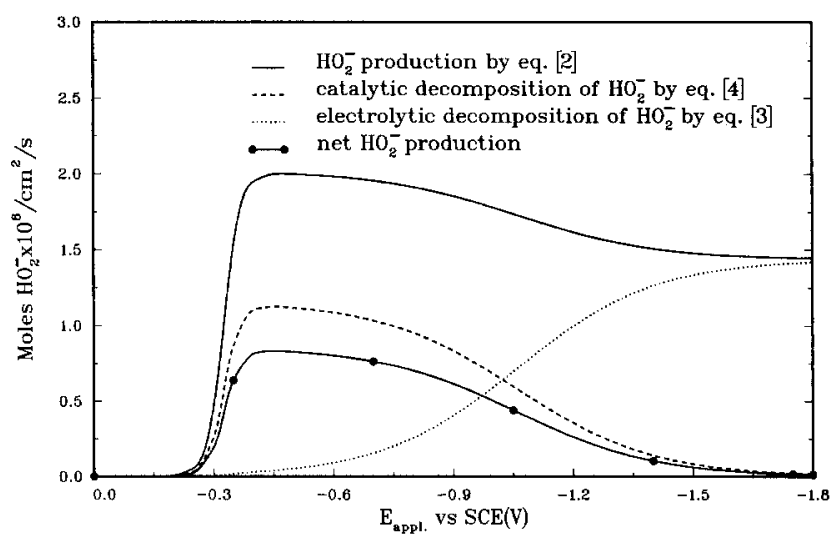

Fig. 12. Production of peroxide in the presence of catalytic decomposition of peroxide. Simulation parameters: $i_{02, \text { ref }}=1.0 \times 10^{-8} \mathrm{~A} / \mathrm{cm}^{2}$, $\alpha_{\mathrm{c} 2}=1.20, i_{03, \mathrm{ref}}=1.0 \times 10^{-12} \mathrm{~A} / \mathrm{cm}^{2}, \alpha_{\mathrm{a} 3}=0.15, \Omega=3600 \mathrm{rpm}$. 
resents the rate of peroxide decomposition by reaction [4]. This decomposition reaction generates $\mathrm{O}_{2}$ which is recylced and reduced again to peroxide, leading to an enhancement in the peroxide production rate as indicated by the solid curve. The net peroxide production rate however, is considerably lower as a result of the loss of peroxide by reaction [4].

\section{Summary}

A general model that can be used to simulate the polarization curves of $\mathrm{O}_{2}$ reduction in alkaline electrolytes has been presented. The nature of the curves demonstrates the complexity of the $\mathrm{O}_{2}$ reduction reaction. The catalytic regenerative reaction enhances the polarization curves in the potential region where peroxide is produced. The hump that is sometimes observed in the polarization curves for $\mathrm{O}_{2}$ reduction can be attributed to the competition for the $\mathrm{O}_{2}$ species at the electrode surface between the direct $4 e^{-}$process and the consecutive $2 e^{-}$ process.

\section{LIST OF SYMBOLS}

$c_{i} \quad$ concentration of species $\mathrm{i}, \mathrm{mol} / \mathrm{cm}^{3}$.

$D_{i} \quad$ diffusion coefficient of species $\mathrm{i}, \mathrm{cm}^{2} / \mathrm{s}$

$D_{\mathrm{R}} \quad$ diffusion coefficient of limiting reactant, $\mathrm{cm}^{2} / \mathrm{s}$

F Faraday's constant, $96,487 \mathrm{C} / \mathrm{mol}$

$i_{1} \quad$ local current density due to reaction $\mathrm{j}, \mathrm{A} / \mathrm{cm}^{2}$

$i_{0, j} \quad$ exchange current density due to reaction $j$ at surface concentrations, $\mathrm{A} / \mathrm{cm}^{2}$

$i_{o j, \text { ref }}$ exchange current density due to reaction $\mathrm{j}$ at reference concentrations; $\mathrm{A} / \mathrm{cm}^{2}$ total current density, $\mathrm{A} / \mathrm{cm}^{2}$

$m$ number of charge transfer reactions at electrode surface

$N_{\text {i }} \quad$ flux of species i, $\mathrm{mol} / \mathrm{cm}^{2} / \mathrm{s}$

$n_{\mathrm{j}} \quad$ number of electrons transferred in reaction $j$

$p$ reaction order with respect to catalytic decomposition of $\mathrm{HO}_{2}^{-}$

$R \quad$ universal gas constant, $8.314 \mathrm{~J} / \mathrm{mol} / \mathrm{K}$

$R_{\mathrm{i}} \quad$ homogeneous rate of consumption of species $\mathrm{i}$ in bulk solution, mol/s

$r_{\mathrm{s}}$ catalytic rate of decomposition of $\mathrm{HO}_{2}{ }^{-}$at the electrode surface, $\mathrm{mol} / \mathrm{cm}^{2} / \mathrm{s}$

$s_{i j} \quad$ stoichiometric coefficient of species $i$ in reaction $j$

$T$ absolute temperature, $\mathrm{K}$

$U_{3}$ theoretical open-circuit potential, $\mathrm{V}$

$U_{\mathrm{j}}^{\theta} \quad$ standard electrode potential for reaction $\mathrm{j}, \mathrm{V}$

$y$ distance from electrode surface into electrolyte, $\mathrm{cm}$

\section{Greek}

$\alpha_{a j} \quad$ anodic transfer coefficient for reaction $j$

$\alpha_{c j} \quad$ cathodic transfer coefficient for reaction $j$

$\delta_{\mathrm{D}} \quad$ diffusion layer thickness, $\mathrm{cm}$

$\rho_{0} \quad$ pure solvent density, $\mathrm{kg} / \mathrm{cm}^{3}$

potential in the solution, $\mathrm{V}$

$\Phi_{\text {met }}$ potential of working electrode, $\mathrm{V}$

$\eta_{j} \quad$ overpotential of reaction $j$ corrected for ohmic drop in the solution and measured with respect to a reference electrode of a given kind in a solution at the reference concentrations, $V$

kinematic viscosity, $\mathrm{cm}^{2} / \mathrm{s}$

$\xi \quad$ dimensionless distance from electrode surface

$\Omega$ rotation speed of electrode, $\mathrm{rad} / \mathrm{s}$

$\gamma_{i j} \quad$ reaction order of species $i$ in reaction $j$
Subscripts

o at the electrode surface

j reaction, $j$

re reference electrode

ref reference conditions

$\infty \quad$ in the bulk solution

\section{REFERENCES}

1. Editorial, Consult. Eng., 45, 38 (1981).

2. J. O. Haggin, Chem. Eng. News, 16 (March 12, 1984).

3. L. Gestaut, United States Department of Energy Contract DE-AC03-76SF00098 (Sept. 1983)

4. A. C. Tseung and S. M. Jasem, J. Appl. Electrochem., 11, 209 (1981).

5. D. B. Sepa, M. V. Vojnovic, and A. Damjanovic, Electrochim. Acta., 26, 781 (1981).

6. D. B. Sepa, M. V. Vojnovic, and A. Damjanovic, ibid., 25, 1491 (1980); and ibid., 11, 967 (1966).

7. J. Zagal, P. Bindra, and E. Yeager, This Journal, 127, 1506 (1981).

8. J. Heyrovsky, Trans. Faraday Soc., 19, 785 (1924).

9. O. Spalek, J. Balej, and K. Balogh, Collect. Czech. Chem. Commun., 42, 952 (1977).

10. E. B. Yeager, United States Department of Energy Contract EC-77-C-02-4146, Oct. 1977-Sept. 1978.

11. G. Ostrovida and G. Vitvitskaya, Soviet Electrochem., 6, $1085(1970)$.

12. M. Brezina and J. Phuong, J. Electroanal. Chem. Interfacial Electrochem., 40, 107 (1972).

13. J. D. E. McIntyre, J. Phys. Chem., y1, 1196 (1967)

14. J. D. E. McIntyre, ibid., 73, 4102 (1969).

15. K. F. Blurton and E. McMullin, This Journal, 116, 1476 (1969).

16. A. J. Appelby and M: Savy, J. Electroanal. Chem. Interfacial Electrochem., 92, 15 (1978).

17. A. Damjanovic, M. A. Genshaw, and J. O'M. Bockris, This Journal, 114, 1107 (1967).

18. V. S. Bagotskii, M. R. Tarasevich, and V. Yu. Filinovskii, Elektrokhimiya., 5, 1218 (1969).

19. H. S. Wroblowa, Y. C. Pan, and Razumney, J. Electroanal. Chem. Interfacial Electrochem., 69, 195 (1976).

20. R. C. M. Jakobs, L. J. J. Jansen, and E. Barendrecht, Electrochim. Acta, 30, 1085 (1985).

21. P. K. Adanuvor, R. E. White and S. Lorimer, Submitted to This Journal, 134, 625 (1987).

22. W. C. Schumb, C. N. Satterfield, and R. L. Wentworth, "Hydrogen Peroxide," Reinhold Publishing Co., New York (1955)

23. K. Goszner, D. Korner, and R. Hite, J. Catal., 25, 245 (1972).

24. M. K. Tham, R. D. Walker, and K. E. Gubbins, J. Phys. Chem., 74, 1747 (1970).

25. R. E. Davis, G. L. Horvath, and C. W. Tobias, Electrochim. Acta, 12, 287 (1967).

26. M. Brezina, J. Korta, and M. Musilova, Collect. Czech. Chem. Commun., 33, 3397 (1968).

27. E. Berl, Trans. Electrochem. Soc., 76, 359 (1939).

28. J. P. Hoare in "Standard Potentials in Aqueous Solutions," A. J. Bard, R. Parson, and J. Jordan, Editors, Marcel Dekker, Inc., New York (1985).

29. E. L. Littauer and K. C. Tsai, Electrochim. Acta, 24, 681 (1979).

30. J. Newman, "Electrochemical Systems," PrenticeHall, Inc., Englewood Cliffs, NJ (1973). 